\title{
THE ROLE OF INTERNAL AND EXTERNAL FACTORS ON MANAGEMENT STUDENTS' SUBJECT CHOICES
}

\author{
David AL Coldwell and Chris W Callaghan
}

School of Economic and Business Sciences, University of the Witwatersrand

Accepted: March 2013

\begin{abstract}
The aim of the study is to investigate undergraduates' perceptions of the comparative worth/utility of studying Business Science disciplines at a prominent South African University in terms of: (i) internal factors comprising aptitudes, values and interests; and (ii) external factors comprising job attractiveness (job prospects, earning potential, non-salary benefits and work-life balance), and (iii) university and discipline academic reputations. The study utilises a specifically designed instrument to measure internal and external factors impinging on career choice. A purposive non-random sample, consisting of 130 second and third year students in Human Resource Management (HRM) and Management, is used. Findings suggest that, while perceptions of aspects of careers, such as job and career prospects generally dominate the choice of major subjects, students studying HRM majors hold community orientated values that distinguish them from their peers. Many students are found to make choices primarily on the basis of their perceptions of 'external factors', rather than their interests. The findings are discussed in terms of extant theory and potential practical outcomes.
\end{abstract}

Key words: Schein, Gottfredson, student perceptions, major subject choice, business science, education

JEL: M210

\section{1}

\section{Introduction}

The human resources management career literature indicates that changes in the structure of organisations have implications for the individuals' career development and career choices (Super, 1980; Brousseau, Driver, Eneroth \& Larsson, 1996; King, 2004; Schein, 1996). The increasing importance of knowledge work requires further research on the development knowledge workers' careers (Van Staden \& Du Toit, 2011) and the conceptions of careers have expanded to encompass both work and non-work related factors (King, 2004). Furthermore, "careers have a personal as well as a vocational meaning for many people; a complete picture of career selfmanagement needs to consider people's aspirations for their lives outside work" (King, 2004:117). Knowledge of student perceptions of the learning process in contemporary tertiary education is an increasingly important area of research (Beckman \& Rayner, 2011; Henige, 2011; Keller, Parker \& Chen, 2011) as it can contribute to improvements in both teaching and learning (Henige, 2011; Tudor, Penlington \& McDowell, 2010). Intrinsic factors specific to the individual, such as selfesteem, can: "influence employability attributes significantly" (Potgieter, 2012:13). This body of career literature reveals the increasing importance of individual perceptions and goals in career choice.

\section{2}

\section{Purpose and objectives of the study}

Although a voluminous literature now exists within Human Resources Management on the burgeoning new development of Career Management as a separate discipline in its own right, the current study returns to some of the founding fathers of the Career Management discipline to gain a clearer insight into the fundamentals of career selection. Gottfredson (1981) suggests that individuals perceive career barriers and on the basis of specific perceptions of these barriers compromise occurs. However, Swanson and Tokar (1991) 
question Gottfredson (1981) and argue that although barriers might be perceived as insurmountable by some, others may regard them as merely challenging. Thus, a tension exists between these conceptions. Gottfredson (1981) suggests that if goals and goalassociated behaviour are adjusted on the basis of perceptions of real life aspects of a career, clearer relationships would be expected between such perceptions and the choice of a major subject at university. Gottfredson (1981) maintains that individual career aspirations develop through a process of 'circumscription' in which an increasingly refined understanding about oneself and the world of work points to specific careers and occupations.

Similarly, Schein (1996) suggests that an individual, at some point of the career /selfmanagement process, will typically begin to make choices related to the pursuit of particular careers. Schein (1996) suggests that the tension between the 'external career' and the 'internal career' brings about certain fundamental shifts in the nature of career choice and development.

Career decisions made prior to entry into a career are considered to be particularly important. The major subject or subjects taken at a higher education level in preparation for employment, can be regarded as indicative of the individual's choice prior to their entry into a career. The 'internal career' "involves a subjective sense of where one is going in one's work life, in contrast to the 'external career,' or the formal stages and roles defined by organisational policies and societal concepts of what an individual can expect in the occupational structure" (Schein, 1996:80). An individual's self-concept is the basis of a 'career anchor', that maintains consistency in a career (Schein, 1996). “A person's career anchor is his or her self-concept, consisting of: 1) self-perceived talents and abilities, 2) basic values, and, most importantly, 3) the evolved sense of motives and needs as they pertain to the career" (Schein, 1996:80). A further differentiation is stressed regarding the core interests of individuals that underpin their career anchors. These core interest anchors are: financial or remuneration interest, job interest and service or community contribution.

To the authors' knowledge, no research has been conducted into the relationship between the individual's perceptions of Schein's (1996) career anchors and subject choices in the South African higher education context. It is maintained that knowledge about the interface between perceptions and career choices is especially salient at certain stages of an individual's career and unrealistic career expectations can result in employee dissatisfaction (Granrose \& Portwood, 1987). The stage at which an individual first decides to take a specific major subject at University impacts significantly on an individual's subsequent career trajectory. However, a challenge exists with regard to subjective career choices at this point of an individual's development. "Most of us are not aware of our career anchors until we are forced to make choices pertaining to self-development, family or career" yet it is "important to become aware of them so that we can choose wisely when choices have to be made", (Schein, 1996:80).

The paper also interrogates Gottfredson's (1981) theory of 'circumscription' by investigating second and third year business science undergraduate students' perceptions of market, personal and institutional factors, and aims to contribute to the literature by testing the conflicting theoretical conceptions of Swanson and Tokar (1991) on the one hand and Gottfredson's (1981) on the other. In a nutshell, the overriding objective of the research is to investigate the career related perceptions of students and how these perceptions influence the choice of major subjects in an academic context. This is achieved by obtaining insight into student perceptions of business science majors and the resulting career aligned choices in terms of attractiveness (Soutar \& Turner, 2002), personal factors (Gottfredson, 1981; Harvey-Beavis \& Robinson, 2000) and institutional factors (Baldwin, 1994).

\section{3}

\section{Problem investigated}

If individual career choices are made based on perceptions of 'external' or job related factors rather than the 'internal' factors of aptitudes, interests and values, a misalignment of students' career aspirations may occur. This 
misalignment could prove wasteful for the country and could generate poorly job fitted individuals with low job satisfaction and productivity. The current research attempts to investigate the nature of the relationship between such 'external' and 'internal' factors in academic major subject choice.

The following research questions are posed:

- To what extent are self-perceptions of aptitudes, values and interests, or 'internal' factors, part of an individual's core career anchor and choice of a specific major subject?

- What specific self-perceptions of 'external' job related factors are associated with the choice of particular career majors?

Individual perceptions that influence major subject choices are usually related to an individual's specific set of interests and values. According to Schwartz (2007), an individual's values are derived from a motivational infrastructure that draws from physiological, psychological and social needs. An individual's specific values endowment is associated with behaviour consistent with those values (Schwartz, 2007). An individual's interests are therefore expected to reflect core individual values.

Perceptions are framed by an individual's subjective experience of the world.

Thus, a further research question is posed:

- What career perceptions are associated with specific job interest anchors?

\section{Development of the hypotheses}

The hypotheses are generated in accordance with the 'internal' and 'external' factor dimensions mentioned above. However, before stating these formally, a brief explanation is warranted of how they were derived from the literature.

A career is "the evolving sequence of a person's work experience over time" and career theory is "the body of all generalisable theory attempts to explain career phenomena" (Arthur, Hall \& Lawrence, 1989:8/9). Arthur et al. (1989) stress the multidisciplinary nature of career theory.

Career theory has traditionally been dominated by the perspective that career outcomes, for both organisations and individuals, are best achieved through an alignment between the “individual's characteristics and the demands, requirements, and rewards of the organisational environment" (Betz, Fitzgerald \& Hill, 1989: 26). Theory and research findings associated with this perspective have focussed on individual trait differences in relation to career selection (Betz et al., 1989).

One aspect of trait-factor theory concerns individual abilities, such as verbal, numerical, and spacial abilities (Betz et al., 1989). Swanson and Tokar (1991) found common factors to be associated with student concerns about career barriers, such as those related to their ability and job market availability. On the basis of a review of the career literature, Betz et al. (1989) point to research findings that indicate that five to fifteen percent of the variance in performance is explained by ability. Thus, it seems reasonable to expect that individuals include perceptions of aptitudes in their career decisions. The following hypothesis (shown in the form of its null hypothesis) is generated to test this 'internal' factor aspect:

$H^{o a}$ : There is a significant difference between perceptions of aptitude by major academic field subject choice.

Evidence supports the link between individual interests and job satisfaction and tenure in careers (Betz et al., 1989). Needs, values and preferences relate to intrinsic or extrinsic outcomes associated with a career choice (Betz et al., 1989). Mismatches between the individual and the characteristics of a job associated with a particular career are related to dissatisfaction and turnover (Betz et al., 1989).

Betz et al. (1989) argue that the theory of work adjustment is the most comprehensive of the trait-factor theories. A central tenet of this theory is that work adjustment on the job is a function of two employee characteristics: satisfactoriness and satisfaction in an interactional relationship with the work environment (Betz et al., 1989). Satisfactoriness, or the successful performance of job responsibilities, is a function of an individual's abilities and the ability requirements of the job (Betz et al., 1989). Satisfaction is a function of the alignment between an individual's vocational needs and values with the work environment (Betz et al., 1989). Abilities and aptitudes are significant aspects of career theory, but also 
salient are an individual's vocational needs and values.

An individual often makes career choices based on interests and values, which are typically underpinned by motivations (Schwartz, 1992; 2007).

Three potential career anchor dimensions are investigated in this paper: financial interest orientation, job related interest orientation and service interest orientation. The following 'internal' factor hypothesis is derived from the current body of literature available on the subject:

$H^{o b}$ : There is a significant difference between career anchor interests by major academic field subject choice.

Further support for the inclusion of the dimensions of these interests is offered by Holland's (1973) theory. According to Holland (1973), vocational satisfaction, stability and achievement are dependent upon an alignment between an individual's personality and the working environment.

Congruence between an individual's personality and the work environment will lead to increased tenure, and the environment isl also expected to exert an influence upon the individual towards congruence (Betz et al., 1989).

Career barriers have typically been considered to fall into two types: external, such as wages or discrimination and internal, such as motivation or psychological aspects (Swanson \& Tokar, 1991).

Swanson and Tokar (1991:96) investigated student perceptions of career barriers, and categorised these as: 1) social/interpersonal barriers or "barriers regarding one's family of origin and future marriage and children"; 2) attitudinal barriers defined as "self-concept, interests, and attitudes toward work"; and 3) interactional barriers which are related to demographic characteristics, education, experience and the working environment.

An interaction between these internal factors and perceived career- related obstacles in the socio-economic environment is expected to influence career decisions (Gottfredson, 1981). As career barriers are experienced, individuals compromise their goals (Gottfredson, 1981). For Gottfredson (1981) the weaker self concepts face modification before deeper rooted self-concepts, such as gender, are affected. An individual recognises and responds to different career barriers in the interaction between self-concept and environment (Gottfredson, 1981). Thus, goal adjustment will occur on the basis of an individual's perception of self and the socio-economic environment. Differences between career and major subject choice will be expected to be associated with differences in underlying career related perceptions.

Job prospect perceptions, specific career prospects, specific non-salary work benefits, career specific work-life balance, academic field and programme factors are considered 'external factors'. To test these aspects, the following hypotheses are generated. Each is shown in the form of the null hypothesis.

$H^{0 c}$ : There is no significant difference between perceptions of external career factors and major academic field subject choice.

$H^{0 d}$ : There is no significant difference between perceptions of the relative merit of the academic programme and major academic field subject choice.

$H^{0 e}$ : There is no significant association between perceptions of 'external' career perceptions and 'internal' career job interest career anchors.

The latter hypothesis is included in order to better understand the relationship between 'external' and 'internal' factors tested.

\section{5}

\section{Research Methodology}

The study utilises an exploratory quantitative (numerical) cross sectional (i.e. measurements are taken at one point in time) research design and is 'causal' in so far as it tests specific hypotheses, and the problem is structured (Ghauri \& Gronhaug, 2002).

\subsection{Sample}

The sampling procedure consists of a nonrandom purposive sample aimed at involving all second and third year students studying HRM and Management in the School of Economic and Business Sciences willing to participate in the study. Participation was voluntary and confidential. Second and third year students in HRM and Management were 
considered, of which130 out of 355 possible students comprised the sample. Over a third of the students completed the questionnaire.

The study incorporates a specially developed questionnaire that uses both ten-point semantic differential items and items arranged on a five point Likert-type scale. Likert-type scales ranging from 'strongly agree' to 'strongly disagree', were developed and taken to represent interval data and differences were scaled with equal increments (Stevens, 1946). A ten- point semantic differential scale ranging from 'very poor' to 'excellent' was used for perceptions of personal aptitudes and aspects of university programmes.

The questionnaire incorporates five sections: biographical information, perceptions of market demand, personal work interests and values, perceptions of aptitudes and perceptions of academic programs.

\subsubsection{Details of the respondents}

Fifty-seven percent were female. The proportions and numbers of students with Information Systems, Marketing, Finance, Management, Insurance and Risk and HRM majors are reported in Table 1 .

Table 1

Respondent characteristics

\begin{tabular}{|c|c|c|c|c|c|}
\hline & & \multirow{3}{*}{$\begin{array}{c}\text { Mean } \\
-\end{array}$} & & & \\
\hline & & & \multirow{2}{*}{$\begin{array}{c}\text { Standard } \\
\text { deviation }\end{array}$} & \multirow{2}{*}{$\begin{array}{c}\text { Number } \\
56\end{array}$} & \multirow{2}{*}{$\begin{array}{c}\text { Percentage } \\
43\end{array}$} \\
\hline Gender & Male & & & & \\
\hline 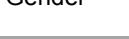 & Female & - & - & 74 & 57 \\
\hline \multirow{6}{*}{ Major type } & I/S & - & - & 20 & 15 \\
\hline & Marketing & - & - & 38 & 29 \\
\hline & Finance & - & - & 49 & 38 \\
\hline & Management & - & - & 61 & 47 \\
\hline & I/R & - & - & 16 & 12 \\
\hline & HRM & - & - & 34 & 26 \\
\hline Age & - & 22.5 & 5.1 & - & - \\
\hline
\end{tabular}

Abbreviations: I/S Information systems; I/R insurance and risk

Students were typically registered for between one and three majors. Three majors were reported by 10.4 percent of the students. Older students are found to choose HRM and Psychology and younger students Economics as major subjects and certain commonalities were found in subject choice combinations.

\subsection{Statistical analyses}

The Statistical analyses involve descriptive and inferential techniques including: reliability analysis, factor analysis, frequencies and calculations of central tendency, correlations and tests of differences by groups. The IBM SPSS statistics 20 package, together with SAS statistical software, was used throughout the research analysis. A univariate analysis gave insight into the central tendency and the dispersion characteristics of the data. Histogram plots were checked for normality. The research included both parametric and non parametric tests. Where non normality in the data was identified non parametric measures were used. ANOVA and t-test procedures were included as part of the initial research process and a univariate analysis was undertaken to check their appropriateness. Distribution plots, such as the probability-probability (P-P) and quantile-quantile (Q-Q) plots, were visually checked. Outliers from the lines generated were noted, and shape differences subjected to further univariate numerical analysis. Descriptive tests for skewness and kurtosis were applied. Data that reflected skewness values that differed from zero, either to the right or to the left, and kurtosis values different from the value of three were investigated further. Skewness and kurtosis statistics for the entire set of variables were obtained. The Shapiro and Wilk test W statistic was used for each of the non binary variables. Data with values away from one or closer to zero were 
identified for further analysis in terms of normality. The sample size of the study $(n=130)$ fell into the range considered appropriate for the Shapiro-Wilk test, that being between 7-2000 data points. Tests of central tendency: the mean, median and mode values were calculated. In the case of a disagreement between the Shapiro-Wilk and the Kolmogorov significance results, the former were accepted. The KolmogorovSmirnov (KS) test of the D statistic was also applied. The SAS procedures also offered the Cramer-von Mises and Anderson-Darling tests. If the KS test results conflicted with these latter tests, this discrepancy is identified and reported. However, in none of the tests was such a discrepancy evident. SAS was used for the descriptive statistics reporting and the P-P and Q-Q plots. All the tested variables showed variation from the P-P and the Q-Q plot lines to some extent, except for the variables entitled 'work life balance for marketing', 'work life balance for finance', 'financial interest orientation' and ' job interest orientation'. The interquartile ranges of the variables were also inspected. On the basis of the univariate testing, relatively few of the items were found to have an underlying distribution approaching acceptable levels of normality. On the basis of this evidence, non parametric alternative tests were used.

Appropriate measures were used for analysing nominal data (Stevens, 1946). Kendall's Tau B measures were used for this purpose.

Parametric tests were excluded on the basis of the univariate evidence which indicated that many of the variables obtained non-normal distributions. Thus, hypotheses a to $\mathrm{d}$ are tested using the Mann Whitney test and Hypothesis e is tested with Kendall Tau correlations.

\subsection{Measuring instrument: reliability and validity}

\subsubsection{Reliability of the external and internal factors' measuring instruments}

Several 'rules of thumb' for Cronbach alpha coefficients have been put forward by various authors. George and Mallery (2003:231) state that coefficient sizes range from $>.9$ (Excellent) to $>.8$ (Good), and from $>.7$
(Acceptable) to >.6 (Questionable); with >.5 (Poor) to $<.4$ (Unacceptable).

Nunnally (1967:226) however, suggests a minimum internal consistency score of .5 as rule of thumb convention for exploratory studies. The Cronbach alpha value for the four job interest scale items was .54. The alpha value for the four financial interest items was .70. The alpha value for the four 'contribution to society' items was .814. These internal consistency coefficients are considered acceptable for an exploratory study.

\subsubsection{Validity of the internal factor 'interest' measuring instrument}

Responses associated with the twelve core interest anchor items were subjected to a factor analysis using a principle components analysis. The assumptions underlying the exploratory factor analysis were checked. Scatterplots were run to check the assumption of linearity. However, it was not possible to ascertain a clear linear pattern in many of the plots. Pearson correlations revealed the presence of inter-item correlations between these items, with these correlations being $>.5$. The antiimage correlation matrix diagonals reported values of well over .5. In terms of further tests of measures of sampling adequacy (MSA), the Kaiser-Meyer-Olkin (KMO) value was found to be .792 , which was greater than the required level of .5, and Bartlett's test of sphericity was found to return an approximate Chi-Square value of 364.191 at 66 degrees of freedom. The Bartlett's test statistic was found to be significant. On the basis of these tests, sampling adequacy was accepted and the analysis was taken to meet the requirements of factorability. A varimax rotation with Kaiser Normalisation was used. These tests were performed using SPSS. The factor solution for the SPSS analysis is shown in Table 2. The ideal typical ratio of 20:1 for cases per item was not met, as 12 items were used with 130 cases. The ratio of cases to items was 10.83:1. This ratio exceeds the reasonable cut-off level for exploratory factor analysis of about 5:1.

The rotated three factor solution is shown in Table 2. This table reports the component loadings together with the communalities (h2) and the total variance, percentage of variance explained and cumulative percentage of variance 
explained in the components. The scale items loaded in a manner consistent with the original conceptualisations and the interpreted simple structure achieved in the factor loadings.

Table 2

Factor analysis rotated component matrix of the career interest orientations

\begin{tabular}{|l|c|c|c|c|c|}
\cline { 2 - 6 } & $\begin{array}{c}\text { Component } \\
\mathbf{1}\end{array}$ & $\begin{array}{c}\text { Component } \\
\mathbf{2}\end{array}$ & $\begin{array}{c}\text { Component } \\
\mathbf{3}\end{array}$ & $\begin{array}{c}\text { Communalities } \\
\text { (h2) squared } \\
\text { multiple } \\
\text { correlation }\end{array}$ & $\begin{array}{c}\text { Communalities } \\
\text { (h2) } \\
\text { extraction }\end{array}$ \\
\hline Total variance explained & 3.4 & 2.1 & 1.2 & - & - \\
\hline $\begin{array}{l}\text { Percentage of variance } \\
\text { explained }\end{array}$ & 28.1 & 17.8 & 10 & - & - \\
\hline $\begin{array}{l}\text { Cumulative percentage of } \\
\text { variance explained }\end{array}$ & 28.1 & 45.9 & 55.9 & - & - \\
\hline Interest: job itself & .209 & -.264 & .364 & 1.0 & .246 \\
\hline Interest: salary & -.063 & .652 & .182 & 1.0 & .462 \\
\hline Interest: societal contribution & .817 & -.154 & .138 & 1.0 & .710 \\
\hline Interest: good money & -.225 & .599 & -.040 & 1.0 & .411 \\
\hline $\begin{array}{l}\text { Interest: make a difference in } \\
\text { peoples' lives }\end{array}$ & .715 & -.145 & .316 & 1.0 & .633 \\
\hline Interest: interesting job & .285 & .164 & .534 & 1.0 & .393 \\
\hline Satisfaction from job itself & .056 & -.197 & .770 & 1.0 & .635 \\
\hline Kind of work is most important & .097 & .271 & .750 & 1.0 & .646 \\
\hline Success defined by salary & .003 & .818 & -.114 & 1.0 & .682 \\
\hline Education to benefit society & .812 & -.058 & -.044 & 1.0 & .664 \\
\hline Happiness is good salary & -.068 & .752 & .014 & 1.0 & .570 \\
\hline Enhance the community & .761 & -.072 & .268 & 1.0 & .657 \\
\hline
\end{tabular}

Component 1: Contribution to society interest orientation; Component 2: Financial interest orientation; Component 3: Job itself interest orientation.

Table 2 indicates that Factor 1 comprised all of the 'contribution to society' items. Factor 2 comprised all of the 'financial interest' orientation items and all the items of the 'job itself' interest orientation loaded on Factor 3. Table 2 shows that over half the variance $(55.9$ per cent) is explained by the first three components (these component's eigenvalues are $>1$ ). Each of the five hypotheses (a to e) is described in detail in relation to the findings in section 6. For hypotheses a to $\mathrm{d}$, aptitude endowments; internal career anchor interests; external career factors such as job prospects, earnings potential, career prospects, nonsalary benefits and work life benefits; and qualification component are tested for differences by groups. Groups comprised of students with each major in specific combinations. Hypothesis e, which relates to the relationships between internal career anchor interests and external career factors, is tested using an associative measure.

\section{6 \\ Discussion of the findings in relation to the hypotheses}

The results are discussed in relation to the 'internal' and 'external' factor hypotheses. The 'internal' factor hypotheses are discussed first, followed by the external hypotheses.

\subsection{Discussion of the findings in relation to the 'internal' hypotheses}

$H^{0 a}$ : There is no significant difference between perceptions of aptitude by major academic field subject choice.

Table 3 presents significant Mann-Whitney $\mathrm{U}$ test associations between perceptions of aptitude endowments and interest anchors on major subject choice 
Table 3

Mann-Whitney $U$ test statistics: Differences between self-perception internal factors of; financial interest career anchor, interest in the job itself career anchor, in contribution to society career anchor, numerical aptitude, verbal aptitude and spacial aptitude by major subject choice

\begin{tabular}{|l|c|c|c|c|c|c|}
\cline { 2 - 7 } \multicolumn{1}{c|}{} & IS & Mktng & Fin & Mgt & IR & HRM \\
\hline Financial interest anchor & - & - & - & - & - & - \\
\hline Interest in job itself anchor & $1549^{\star *}$ & - & - & - & - & - \\
\hline Interest in contribution society & - & - & - & - & - & $1950^{*}$ \\
\hline Aptitude- numerical & - & $-1339^{*}$ & $2599^{* *}$ & - & - & - \\
\hline Aptitude- verbal & - & - & - & - & - & $2003^{*}$ \\
\hline Aptitude- spacial & - & - & - & - & - & - \\
\hline
\end{tabular}

Notes: Significance $p<0.10^{\wedge} ; p<0.05^{\star} ; p<0.01^{* *} ; p<0.001^{* * *}$. Abbreviations used for this and other tables: Information systems (IS); marketing (Mktng); finance (Fin); management (Mgt); insurance and risk (IR); human resources Management (HRM).

With regard to Hypothesis $H^{0 a}$ the MannWhitney tests indicate that individuals choosing Marketing as a major subject have relatively lower self-perceptions of numerical aptitude (Table 3). The reverse is found for Finance and Economics. And HRM majors hold higher self-perceptions of verbal aptitude. These results are unsurprising given the more quantitative focus of the Finance and Economics curricula and the verbal focus of the HRM curriculum. Self-perceptions of spacial aptitude are not significantly associated with any major subject choice. Gottfredson's (1991) argument supports these findings since career choices are adjusted on self-assessments of fit between aptitudes and specific career demands. On the basis of the 'minimum criterion', the null hypothesis is rejected and the alternative hypothesis is accepted.

$H^{o b}$ : There is a significant difference between career anchor interests by major academic field subject choice.

Table 3 indicates that no significant association was found between financial orientation and choice of major subject. This was surprising, as extrinsic (financial) motivation was expected to influence career choice. It may be that a security/stability aspect to students studying business science majors is more evident than purely financial because the current high levels of unemployment emphasise security and stability of employment rather than pure financial reward. This is taken to support Gottfredson's (1981) basic idea of career negotiation in response to changing circumstances. Schein's (1996) argument that an individual's goals, underpinned by an individual's core career anchor, will become the strongest influence upon his/her career decisions, and over time may also be evident as many current students appear to look to degree qualifications as a ticket out of their impoverished socioeconomic backgrounds.

The only significant association between job-related interest and the choice of a major subject is found to be with IS (Table 3). This indicates that interest in IS may be a fundamental driver of this particular career choice. The absence of significance between interests and the other major subject choices suggests that such choices are not primarily made on the basis of job interest. These findings seem to indicate, in line with Gottfredson (1981) that perceptions of core career related differences are more strongly associated with academic major subject choice than with job interest per se.

Table 3 also indicates that community interest (contribution to society) is associated with HRM as a major subject, which supports Schein's (1996) sense of service or dedication to a cause career anchor. Thus, although most evidence appears to support Gottfredson's (1981) notion of gradual adjustment and negotiation of appropriate careers over time, for HRM majors there seems to be an underlying career anchor guiding individuals to select this specialisation. On the basis of the 'minimum criterion', the null hypothesis is rejected and the alternative hypothesis is accepted.

\subsection{Discussion of the findings in relation to the 'external' hypotheses}

$H^{0 c}$ : There is no significant difference between 
perceptions of external career factors by major academic field subject choice.

Table 4 indicates hypothesis $H^{0 c}$, which is discussed in terms of the 'external' dimensions of: job prospects, future earning potential, career prospects. Non-salary benefits and work-life balance aspects of this hypothesis are discussed in relation to the Mann-Whitney test findings displayed in Table 5.

Table 4

Mann-Whitney $U$ test statistics: Differences between external factors of: perceived job prospects; earning potential and career prospects by major subject choice

\begin{tabular}{|c|c|c|c|c|c|c|}
\hline Variables & IS & Mktng & Fin & Mgt & IR & HR \\
\hline \multicolumn{7}{|l|}{ Job prospects (JP) } \\
\hline JP information systems. & $1467^{\star *}$ & & & & & \\
\hline JP marketing & & $2272^{\star \star *}$ & & & & \\
\hline JP finance & & & $2332^{*}$ & & & \\
\hline JP management & & & $-1457^{\star}$ & & & \\
\hline JP human resources & & & & & & $.341^{* * *}$ \\
\hline JP insurance \& risk & & $-1166^{*}$ & & & & \\
\hline \multicolumn{7}{|l|}{ Earnings Potential (EP) } \\
\hline EP information systems & $1355^{\star}$ & & & & & \\
\hline EP marketing & & $2310^{* \star *}$ & & & & \\
\hline EP human resources & & & & & & $2017^{* *}$ \\
\hline \multicolumn{7}{|l|}{ Career prospects (CP) } \\
\hline CP information sys. & $1552^{* * *}$ & & & & & \\
\hline CP marketing & & $2335^{\star \star *}$ & $-1347^{*}$ & & & \\
\hline $\mathrm{CP}$ management & & & & $2411^{*}$ & & \\
\hline $\mathrm{CP}$ human resources & & & & & & $2015^{\star *}$ \\
\hline
\end{tabular}

Notes: significance $p<0.10^{\wedge} ; p<0.05^{*} ; p<0.01^{* *} ; p<0.001^{* * *}$

\section{Job prospects}

Mann-Whitney test results, as indicated in Table 4, suggest a general correspondence between the external factor component perceptions of job prospects and the choice of each major subject, except Management and Insurance \& Risk Management. The latter were, however, found to indicate higher perceptions of job prospects for Finance. Economics as a major subject was included in certain of the analyses in order to gain further insight into extant relationships. Marketing students perceived Insurance \& Risk to offer fewer job prospects. Students with Economics as a major were found to perceive that IS and HRM offer less in terms of job prospects. Thus, the statistically significant associations between the perceptions students have of job prospects and their major subject choices appear to support Gottfredson's (1981) theory. All business science major students, with the exception of Management, exhibit a statistically significant association between perceptions of job prospects in their field and their choice of a major subject associated with such a field. A possible reason for this exception, is that Management is a more generic skill that does not qualify an individual for a specific professional role.

\section{Future earnings potential}

The perceptions of students with Economics and Psychology as major subjects were included for completeness. Individuals with Economics majors perceived IS, Marketing and HRM to have relatively low earning potential. IS, Marketing and HRM majors perceived their career streams to offer relatively high earning potential. However, Finance, Management and IR majors were not significantly associated with perceptions of higher relative career earning potential. Psychology majors also perceived HRM as a high earning potential career stream. These results are taken to give general support to 
Gottfredson's (1981) hypothesis; that the process of confronting career perceptions leads to adjustments in career choices.

\section{Career prospects}

Career prospects typically relate to a broader range of work opportunities than do job prospects. It is expected that the core career anchor of an individual will emerge more strongly over time (Schein, 1996). Certain major subjects maybe perceived to provide more long-term opportunities for certain students. Mann-Whitney test results (Table 4) show that IS, Marketing, Management, and HRM majors each perceived their career prospects to be relatively high.

Gottfredson's (1981) hypothesis seems to be supported in these findings as the majority of subject majors are significantly associated with perceptions of specific career prospects.

Table 5 indicates the findings relating to non-salary benefits and work/life balance external factors pertaining to hypothesis $H^{0 c}$.

\section{Table 5}

Mann-Whitney $U$ test statistics: Differences in external factors of non- salary benefits and work life balance by major subject choice.

\begin{tabular}{|l|c|c|c|c|c|c|}
\cline { 2 - 7 } \multicolumn{1}{l|}{} & IS & Mktng & Fin & Mgt & IR & HR \\
\hline Non salary benefits (NSB) & & & & & & \\
\hline NSB information systems & $1442^{\star *}$ & & & & & \\
\hline NSB marketing & & $1185^{\star}$ & $-2031^{*}$ & & & \\
\hline NSB finance & & & & & & $-1050^{*}$ \\
\hline NSB HR & & & & & & $.1860^{*}$ \\
\hline Work life balance (WLB) & & & & & & \\
\hline WLB marketing & & & & & & $-1039^{*}$ \\
\hline
\end{tabular}

Notes: significance $p<0.10^{\wedge} ; p<0.05^{*} ; p<0.01^{* *} ; p<0.001^{* \star *}$

\section{Non salary work benefits}

Individuals with IS, Marketing and HRM are found to have perceptions of high non-salary benefits associated with their career streams (Table 5). Of the non business science students, Economics majors perceived Marketing to have relatively lower levels of non-salary benefits. These significant associations are also taken to support Gottfredson's (1981) hypothesis.

\section{Work-life balance}

HRM majors perceive lower levels of work life balance to be associated with a career in Marketing (Table 5). There is little evidence suggesting that students adjust their goals and choose subject majors on the basis of work-life balance (Gottfredson, 1981).

On the basis of these significant associations, the null hypothesis is rejected and Gottfredson's (1981) hypothesis of dynamic career adjustment is supported.

$H^{0 d}$ : There is no significant difference between perceptions of the relative merit of the academic programme by major academic field subject choice.

Table 6 shows the findings of Mann-Whitney tests relating to hypothesis $H^{0 d}$

\section{Table 6}

Mann-Whitney U test statistics: Differences between perceptions of the relative merit of the academic programme by major subject choice.

\begin{tabular}{|l|c|c|c|c|c|c|}
\cline { 2 - 7 } \multicolumn{1}{c|}{} & IS & Mktng & Fin & Mgt & IR & HR \\
\hline HRM curriculum & & & & $-714^{* *}$ & & $1537^{* * *}$ \\
\hline HR qualification status & & & & $-716^{* \star}$ & & $1406^{* \star}$ \\
\hline School status & $-764^{*}$ & & & & & \\
\hline
\end{tabular}


Table 6 indicates that HRM majors perceived the status of the university's HRM qualifycation and curriculum content positively. Management majors, however, perceived the opposite. Economics majors perceived the HRM curriculum negatively while Psychology majors perceived it positively. IS majors had lower perceptions of the school's status as a whole. Thus the null hypothesis is rejected.

$H^{0 e}$ : There is no significant association between perceptions of 'external' career perceptions and 'internal' career job interest career anchors.

This hypothesis was derived from the third research question: what career perceptions are associated with specific job interest anchors? It relates to both internal and external factor dimensions.

Table 7 indicates the findings relating to this hypothesis.

Table 7

Kendall's Tau correlations: Associations between career interest orientation anchors and job prospects, earning potential and qualification status

\begin{tabular}{|c|c|c|c|}
\hline Variables & Financial/salary & Job itself & Community/service \\
\hline \multicolumn{4}{|l|}{ Job prospects (JP) } \\
\hline JP information systems & & $.158^{*}$ & $.164^{*}$ \\
\hline \multicolumn{4}{|l|}{ Earning potential (EP) } \\
\hline EP information systems & & $.175^{*}$ & \\
\hline EP human resources management & & $.212^{*}$ & \\
\hline EP insurance and risk & $-.140^{*}$ & & \\
\hline \multicolumn{4}{|l|}{ Career prospects $(\mathrm{CP})$} \\
\hline $\mathrm{CP}$ information systems & $-.151^{*}$ & $.200^{\star *}$ & \\
\hline \multicolumn{4}{|l|}{$\mathrm{CP}$ marketing } \\
\hline \multicolumn{4}{|l|}{$\mathrm{CP}$ management } \\
\hline $\mathrm{CP}$ human resources management & & $.244^{\star \star *}$ & $.142^{*}$ \\
\hline $\mathrm{CP}$ insurance and risk & $-.151^{*}$ & & \\
\hline Interest in job itself & & & $.310^{\star \star *}$ \\
\hline Interest in financials & & & $.132^{*}$ \\
\hline HRM qualification status & & & $.190^{*}$ \\
\hline
\end{tabular}

Notes: Significance $p<0.10^{\wedge} ; p<0.05^{\star} ; p<0.01^{* *} ; p<0.001^{\star * *}$

Table 7 shows that students with a financial job interest have lower perceptions of the earning potential of IR and the career potential of IS and IR. A financial job interest is not found to be associated with any particular aptitude, nor any positive perception of careermajor associations. An interest with the job itself is positively related to perceptions of higher job prospects in IS and a higher earning potential as well as career prospects in HRM. Community service orientation is associated with perceptions of higher job, career and earning prospects for IS, and higher career prospects for HRM. A community service orientation was found to be positively associated with an interest in the job itself and the HRM, and negatively associated with a financial interest orientation. The central concern of individuals with a financial job interest seems to be framed negatively with regard to the earning prospects and career prospects of other fields. This may reflect some aspect of the associations between career perceptions and value orientation (Schwartz, 1992). Individuals with a job interest and community service orientation are positively and primarily focused on IS and HRM respectively. This suggests a congruency of values between these majors and the values of service and job interest as career anchors. Congruence between individual needs or interests and job characteristics is expected to result in greater job involvement (Govender \& Perumasur, 2010). In general, Gottfredson's (1981) thesis is supported by these findings. On the basis of these results the null hypothesis is rejected and the alternative hypothesis is accepted. 
On the basis of the results of the tested hypotheses, students' perceptions of career prospects and earning potential appear to dominate the underlying interest in the job itself and of specific major-career associations.

\section{7}

\section{Conclusion}

The findings tentatively suggest that consonance in the scores of tests to establish the perceptions of real job aspects of careers by majors across the board support Gottfredson's (1981) hypothesis of progressively negotiated career anchors. The almost total absence of dissonance between perceived aptitudes and major subjecst chosen contests Swanson and Tokar's (1991) notion of choosing a career as a 'challenge' rather than as a dynamic and negotiated adjustment over time. Students who chose HRM as a major, in particular appear to have career aspirations most aligned with internal personal factors relating to selfperceptions of aptitudes, values and interests.

Finance majors perceived the career prospects of other majors negatively. Job interest and service were found to frame perceptions positively among IS and HRM majors.

In terms of external factors, the findings suggest that self perceptions of aptitudes underpinning particular academic major choices are broadly consonant with the perceptions of job prospects, earning potential, career prospects, non salary work benefits, and work life balance perceptions of specific careers. And, perceptions of aptitudes appear to be particularly important in major/career selection. In general, the evidence supports Gottfredson's (1981) hypothesis that self-perceptions generate adjustments in the selection of particular careers. Schein's (1996) evolutionary perspective of a process of negotiation and discovery of core career anchors is thus vicariously supported by the findings.

In very general terms, the findings suggest that students select majors that underpin particular business careers on the basis of perceived aptitudes; perceived job, earning and career prospects and,; more tentatively, the career anchors of security/stability (Finance, Economics, Insurance \& Risk Management, Marketing), technical/functional competence
(IS and Management), entrepreneurial creativity (Management) and service/dedication to a cause (HRM).

Students selecting Finance, as well as Economics and Insurance \& Risk Management appear to have security and stability anchors, possibly arising from specific socio-economic circumstances and the prevailing high unemployment rate in South Africa. These potentially financially rewarding specialisations are chosen by students to find a way out of the precarious socio-economic conditions many of them currently face. This is an overriding goal that may subordinate personal interest in the job itself. Those with lesser numerical and/or verbal aptitudes perhaps see their career objectives more in terms of interest in the job itself (IS) and service/dedication to a cause.

In an exploratory study of this type, there are bound to be limitations in the research process. In this case, perhaps the most prominent is that the study is limited to an investigation of business science majors at one university. The sample is also quite small and is not selected randomly from the population of business science students (although given its proportionate size, it seems reasonable to consider it representative of that population).

The study is cross sectional and is thus limited to perceptions of students at one point in time. A longitudinal cohort analysis of student career aspirations on the basis of particular self- perceptions and changing market and/or institutional factors would present more powerful empirical evidence for testing Gottfredson's (1981) theory of circumscription.

The study is restricted to the use of exploratory type statistical procedures involving exploratory factor and item analyses to test the validity and reliability of the measuring instruments. The empirical data analysis also adopts statistical techniques that aim to expose underlying associations between the selected variables defined by the hypotheses, thus necessitating a number of exploratory initial hypotheses. The establishment of the particular associations discovered in the analyses enhance the possibility of generating a model that has an empirically verified structure defined by more refined statistical techniques, such as those provided by structural equation modeling. 
The exploratory findings also suggest that further research could fruitfully be applied to an analysis of the mechanisms of nascent career choice by university students selecting particular business science and other majors at other universities. This may best be conducted using a structural equation statistical analysis built from the basic model provided in the current exploratory analysis. Moreover, a longitudinal rather than a cross sectional analysis could be used to plot students' career negotiation processes as they unfold. Possible outcomes of such research would include aiding students in selecting appropriate careers by studying majors more in line with internal personal interests and attributes than external market and/or institutional factors; generating the prospect of career satisfaction and industrial employment stability and productivity.

\section{References}

ARTHUR, M.B., HALL, D.T. \& LAWRENCE, B.S. (eds.) 1989. Handbook of career theory. Cambridge: Cambridge University Press.

BALDWIN, G. 1994. The student as customer: the discourse of 'quality' in higher education. Journal of Tertiary Education Administration, 16(1):125-133.

BECKMAN, J. \& RAYNER, G. 2011. Embedding academic-professional collaborations that build student confidence for essay writing: Student perceptions and quality outcomes. A practice report. The International Journal of the First Year in Higher Education, 2(2):83-89.

BETZ, N.E., FITZGERALD, L.F. \& HILL, R.E. 1989. Trait-factor theories: traditional cornerstone of career theory. in Arthur, M.B., Hall, D.T. \& Lawrence, B.S. (eds.) Handbook of career theory. Cambridge: Cambridge University Press.

BROUSSEAU, K.R., DRIVER, M.J., ENEROTH, K. \& LARSSON, R. 1996. Career pandemonium: realigning organizations and individuals. The Academy of Management Executive, 10(4):52-66.

GEORGE, D. \& MALLERY, P. 2003. SPSS for Windows step by step: A simple guide and reference, Boston: Allyn \& Bacon.

GHAURI, P. \& GRONHAUG, K. 2002. Research methods in business studies. Prentice Hall: Harlow. GOTTFREDSON, L.S. 1981. Circumscription and compromise: A developmental theory of occupational aspirations. Journal of Counselling Psychology, 28:545-579.

GOVENDER, S. \& PARUMASUR, S.B. 2010. The relationship between employee motivation and job involvement. South African Journal of Economic and Management Sciences, 13(3):237-253.

GRANROSE, C.S. \& PORTWOOD, J.D. 1987. Matching Individual career plans and organizational career management. The Academy of Management Journal, 30(4):699-720.

HARVEY-BEAVIS, A. \& ROBINSON, 2000. Views and influences: Tertiary education, secondary students and their advisers. Canberra: Commonwealth Department of Education, Training and Youth Affairs.

HENIGE, K. 2011. Undergraduate student attitudes and perceptions toward low- and high- level inquiry exercise physiology teaching laboratory experiences. Advanced Physiology Education, 35:197-205.

HOLLAND, J.L. 1973. Making vocational choices. Prentice Hall; Englewood Cliffs.

International Journal of Education Management, 16(1):40-45.

KELLER, S., PARKER, C.M. \& CHEN, C. 2011. Employability skills: student perceptions of an IS final year capstone subject. Available at: http://www.ics.heacademy.ac.uk/italics/vol10iss2.htm [accessed 2012-7-30].

KING, Z. 2004. Career self-management: Its nature, causes and consequences. Journal of Vocational Behavior, 65:12-133.

NUNNALLY, T. 1967. Psychometric theory. New York: McGraw-Hill.

POTGIETER, I. 2012. The relationship between the self-esteem and employability attributes of postgraduate business management students. SA Journal of Human Resources Management/SA Tydskrif vir Menslikehulpbronbestuur, 10(2), Art. \#419. Available at: http://dx.doi.org/10.4102/sajhrm.v10i2.419 [accessed 2012-7-30].

SCHEIN, E. H. 1996. Career anchors revisited: implications for career development in the 21 st century. The Academy of Management Executive, 10(4):80-88. 
SCHWARTZ, S. H. 1992. Universals in the content and structure of values: Theory and empirical tests in 20 countries. In M. Zanna (Ed.), Advances in experimental and social psychology (25:1-65). New York: Academic Press.

SCHWARTZ, S.H. 2007. Value orientations-measurement, antecedents and consequences across nations. in Jowell, R. (ed.) Measuring attitudes cross-nationally. Lessons from the European Social Survey. Los Angeles: Sage.

SOUTAR, N.G. \& TURNER, J.P. 2002. Students' preferences for University: a conjoint analysis. International Journal of Education Management, 16(1):40-45

STEVENS. S.S. 1946. On the theory of scales of measurement. Science, 103(2684):677-600.

SUPER, D.E. 1980. A life-span, life-space approach to career development. Journal of Vocational Behavior, 16:282-298.

SWANSON, J.L. \& TOKAR, D.M. 1991. College students' perceptions of barriers to career development. Journal of Vocational Behaviour, 38:92-106.

TUDOR, J., PENLINGTON, R. \& MCDOWELL, L. 2010. Engineering education. Journal of the Higher Education Academy Engineering Subject Centre, 5(2):69-72.

VAN STADEN, R. \& DU TOIT, A. 2011. Career development of South African knowledge workers. South African Journal of Economic and Management Sciences, 14(1):80-91. 